\title{
Odds to Quicken Reporting Already Delayed Cases: Acquired Immune Deficiency Syndrome Incidences are Illustrated
}

\author{
Ramalingam Shanmugam \\ School of Health Administration, Texas State University-San Marcos, TX 78666, USA
}

Received 2012-08-24, Revised 2012-08-29; Accepted 2013-04-01

\begin{abstract}
Delayed reporting in a medical system complicates efforts to estimate the number of cases that occurred in a time period. A case in point is the government's difficulty to estimate the number of Acquired Immune Deficiency Syndrome (AIDS) cases. The reporting delays are not intentional but are ongoing due to changing Federal regulations or medical definitions of the case like AIDS. To simplify the complications, this article approaches by modifying the geometric distribution. To be specific, let $0<1-\theta<1$ is a chance for a case (like AIDS) to be reported in the same time period of its occurrence to a (Federal or other) agency. If the reporting is missed in its occurrence time period, the case gets reported in a next or later time period. Let $\mathrm{Y}$ be the number of time periods skipped until its reporting. In this process, the reporting probability in a current period is chained with that of past period with an "odds of quickening" to report. The implication and significance of "quickening odds" are investigated and explained in this article, using the AIDS data with delayed reporting.
\end{abstract}

Keywords: Geometric Distribution, Survival Function, Medical System's Memory, Nuisance Parameter

\section{INTRODUCTION}

Who might have guessed in year 1981 that more than 45 million people would have died and another estimated 75 million people would have suffered worldwide with "Acquired Immune Deficiency Syndrome (AIDS)"? What is the genesis of AIDS? On June 5, 1981, the Center for Disease Control (CDC) first detailed the biopsy of "5 young men with a rare pneumonia". After failed immune system, their vital $\mathrm{CD}^{+}$cells were invaded by viruses, bacteria, fungi and parasites. CDC (1985) and Chamberland et al. (1985) for details. The virus was detected by a Polymerase Chain Reaction (PCR). Later in June, 1982 the CDC (1985) announced that the world faced "a new, deadly sexually transmitted disease". A month later, the CDC coined the name: "Acquired Immune Deficiency Syndrome (AIDS)" to refer this illness.

The World Health Organization (WHO) estimated that about 33.4 million people were suffering with AIDS and two million people (including 330,000 children) died in 2009 alone. The AIDS has become a major deadly human illness in many parts of the world. A scary fact is that AIDS is spreading. The AIDS diagnosis is based on clinical symptoms which appear to vary with lag effects since an initial infection. The medical community periodically debates and perfects the definition of clinical symptoms and recommends that a person with the virus should be declared as an AIDS case only after the illness progressed enough to pass through benchmarks determined by the CDC (1985). The Federal government regulated that the laboratory evidence of the virus should no more be mandated to report an AIDS case. This cautionary federally imposed tedious approach causes an unavoidable reporting delay of AIDS cases. The CDC (1985) mentions that while 42,670 AIDS cases were diagnosed by physicians as of 31 March 1987 but only 33,350 of them were actually reported. Some AIDS cases are never reported while others are reported in any of the subsequent sixteen quarters (Hay and Wolak (1994) for data and their details).

The reporting delays result in practical difficulties to estimate the actual number of AIDS cases. Harris (1990) noticed that the reporting delays of even 0.6 months shifted the frequency trend of AIDS cases to the right and consequently, the estimated AIDS cases fell far 
below the actual number. DeGruttola et al. (1992) reported that the number pediatric AIDS cases in New York City were under-estimated because of reporting delays which changed over the chronological time in a non-stationary manner. Lindsey (1996) considered bivariate intensity functions of non-stationary Poisson processes and a non-parametric methodology to undo the under-estimation of AIDS cases due to reporting delays. Pagano et al. (1994) developed a regression methodology to make an adjustment to an under-estimate of the completely unobservable actual number of AIDS cases because of reporting delays. Bacchetti (1996) identified that the 1993 re-definition of AIDS caused reporting delays and also disrupted the interpretations of the death trend of AIDS cases. Gebhardt et al. (1998) noticed based on a Bayesian generalized linear model on reverse-time hazards that many industrial countries including Switzerland and Spain incurred significant deaths because of AIDS but it was understood only much later because of reporting delays. Tabnak et al. (2000) developed a change-point model to correct a biased estimate of AIDS cases because of reporting delays. Cui (1999) developed a nonparametric method to analyze Australian left-censored and right-truncated AIDS data and estimated the impact of the reporting delays.

The reporting delays occur in other topics also. Lawless (1994) mentioned that reporting delays occurred in insurance claims and provided a method to model the random temporal fluctuations to compensate for the under-reported claims. MacArthur et al. (1985) traced the source of under-reporting of tumor and other cancers and found that the hospitals rather than the patients cause reporting delays. Clegg et al. (2002) pointed out that reporting delays occur in cancer reporting medical after informing that the reporting delays actually confused the health officials to comprehend the cancer incidence trend as they contained estimation errors with downwardly biased cancer incidence trends and provided an approach with an appropriate methodology to obtain reporting-erroradjusted cancer incidence rate. Midthune et al. (2005) provided a methodology to make adjustments for an accurate cancer incidence rate in general and melanoma cancer in particular in the U.S. Zou et al. (2009) provided a methodology to capture the effect of reporting year on delay modeling of cancer incidence.

All above mentioned reasons motivate the importance and necessity for an additional statistical methodology to estimate number of cases like AIDS with reporting delays. A new methodology is pursued in this article by modifying geometric distribution to suit the reality in reporting medical system. This modified probability pattern is named Oscillating Geometric Odds
Distribution (OGOD). Benefits include not only a way to estimate the actual number of AIDS cases in a given time period but also offer a statistical methodology to assess the significance of the estimated "odds of quickening" to improve reporting of an already delayed reporting. This methodology helps health administrators to prepare budgets and policies based on a better estimate of the cases like AIDS. Healthcare policies emerge from facts and perceptions. Fan (2004) outline the society's fears and phobias because of threat from AIDS illness. Understanding the AIDS prevalence using OGOD might help to reduce the psychological, social, economic fears or to combat the health insurance industry's denials to deserving applicants with AIDS symptoms. The reporting delay is not unique to AIDS illness alone and is suspected to exist in other illnesses as well. The contents of this article are versatile enough to explain the consequences of reporting delays in engineering, economics, public health, business or other disciplines as well.

The statistical properties of OGOD are derived in section 2 . In section 3 , they are illustrated with the data about reporting delays of AIDS cases in Hay and Wolak (1994). The last section 4 contains conclusive thoughts and recommendations.

\subsection{Oscillating Geometric Odds Distribution}

Let $0<1-\theta<1$ be a probability of reporting a case (like AIDS) in the same period of its occurrence. Delayed reporting in a medical or other system complicates efforts to estimate the actual number of cases that occurred in a time period. Fan (2004) for details. To resolve this difficulty, this article approaches by modifying geometric distribution as follows. The odds of reporting a case in the same period of its occurrence are $\operatorname{odds}_{\theta}=\frac{\theta}{1-\theta}$. Then, a non-negative integer random variable $\mathrm{Y}$, denoting the number of skipped time periods until its reporting follows a reparametrized geometric distribution Equation 1:

$\mathrm{p}(\mathrm{y} \mid \theta)=\operatorname{Pr}[\mathrm{Y}=\mathrm{y}]=\frac{\left(\operatorname{odds}_{\theta}\right)^{\mathrm{y}}}{\left(1+\mathrm{odds}_{\theta}\right)^{\mathrm{y}+1}}$

where, $y=0,1,2, \ldots, \infty ; 0<\theta<1$. The probability of reporting a case in the same period of its occurrence is $\operatorname{Pr}[\mathrm{Y}=0]=\frac{1}{\left(1+\operatorname{odds}_{\theta}\right)}$. Interestingly, the mean $\mu_{\theta}=$ $\operatorname{odds}_{\theta}$. A modification of (1) is necessary to suit an ongoing delayed reporting with an "odds of quickening", odds $_{\phi}=\frac{\phi}{1-\phi}>0$. Consequently, the reporting chance 
undergoes a fluctuation in the coming time periods. The fluctuations contradict the memory less property of geometric distribution (1). What is memory less property? It means the conditional probability of reporting a case in a time period given it has not been reported so far since its occurrence equals its unconditional probability of reporting in its period of occurrence itself. This is translated in probability terminology below in (2). Note from (1) that Equation 2:

$$
\begin{aligned}
& \operatorname{Pr}[\mathrm{Y} \geq \mathrm{m}+\mathrm{t} \mid \mathrm{Y} \geq \mathrm{m}] \\
& =\frac{\operatorname{Pr}[\mathrm{Y} \geq \mathrm{m}+\mathrm{t} \cap \mathrm{Y} \geq \mathrm{m}]}{\operatorname{Pr}[\mathrm{Y} \geq \mathrm{m}]} \\
& =\left(\frac{\text { odds }_{\theta}}{1+\text { odds }_{\theta}}\right)^{\mathrm{m}}=\operatorname{Pr}[\mathrm{Y} \geq \mathrm{m}]
\end{aligned}
$$

The ongoing delays create a memory in a reporting medical system. Note that odds $s_{\theta}=0$ when the case is reported in the same period of its occurrence and the "odds of quickening" is obsolete. Otherwise, the odds ${ }_{\phi}$ is fused into the reporting probability in a chained manner like:

$$
\begin{aligned}
& \operatorname{pr}(\mathrm{Y}=\mathrm{y}) \\
& =\left\{\begin{array}{c}
\theta^{\mathrm{y}}\left[\operatorname{pr}(\mathrm{Y}=\mathrm{y}-1)+\frac{\phi}{1-\phi}\right] \text { if } \mathrm{y}=1,2, \ldots \ldots \\
\mathrm{y}=0
\end{array}\right.
\end{aligned}
$$

This modification results in a new probability pattern Equation 3:

$$
\begin{aligned}
& \mathrm{p}(\mathrm{y} \mid \phi, \theta)=\operatorname{Pr}[\mathrm{Y}=\mathrm{y}]= \\
& \frac{\left[1+\left(\operatorname{odds}_{\phi}\right)\left(1+\operatorname{odds}_{\theta}\right) \mathrm{y}\right]\left(\operatorname{odds}_{\theta}\right)^{\mathrm{y}}}{\left[1+\left(\operatorname{odds}_{\phi}\right)\left(\operatorname{odds}_{\theta}\right)\left(1+\operatorname{odds}_{\theta}\right)\right]\left(1+\operatorname{odds}_{\theta}\right)^{\mathrm{y}+1}} \\
& \text { with y }=0,1,2, \ldots, \infty ; 0<\theta<1,0<\phi<1 .
\end{aligned}
$$

Is expression (3) a bona fide probability distribution? The answer is affirmative. Trivially, the expression (3) is non-negative. The sum of their values equals one as it is shown below:

$$
\begin{aligned}
& \sum_{\mathrm{y}=0}^{\infty} \mathrm{p}(\mathrm{y} \mid \phi, \theta)=\frac{\left[1+\left(1+\operatorname{odds}_{\theta}\right) \operatorname{odds}_{\phi} \mathrm{y}\right]\left(\operatorname{odds}_{\theta}\right)^{\mathrm{y}}}{\left[1+\operatorname{odds}_{\theta}\left(1+\operatorname{odds}_{\theta}\right) \operatorname{odds}_{\phi}\right]\left(1+\operatorname{odds}_{\theta}\right)^{\mathrm{y}+1}} \\
& =\frac{\left[(1-\theta)+\left(\frac{\phi}{1-\phi}\right)(1-\theta) \theta \partial_{\theta}(1-\theta)^{-1}\right]}{\left[(1-\theta)+\left(\frac{\phi}{1-\phi}\right)\left(\frac{\theta}{1-\theta}\right)\right]}=1
\end{aligned}
$$

where, $\partial_{\theta}$ denotes the derivative with respect to $\theta$. The expression (3) is named "Oscillating Geometric Odds Distribution (OGOD)".
In the absence of "odds of quickening" to report in a system (that is, $\phi=0$ ), the OGOD (3) reduces to the geometric distribution in (1) as a particular case. Otherwise, when all cases are reported in the same period, note that $\mathrm{Y}=0$. The reporting medical system has no lag with a probability Equation 4:

$$
\begin{aligned}
& \mathrm{p}(\mathrm{Y}=0 \mid \phi \neq 0, \theta)=\left[1+\operatorname{odds}_{\theta}\right]^{-1} \\
& {\left[1+\left(\operatorname{odds}_{\theta}\right)\left(1+\operatorname{odds}_{\theta}\right)\left(\operatorname{odds}_{\phi}\right)\right]^{-1}}
\end{aligned}
$$

The probability for a reporting medical system to be busy with a lag of cases to report is Equation 5:

$$
\begin{aligned}
& \mathrm{p}(\mathrm{Y} \geq 1 \mid \phi \neq 0, \theta)=1-\left[1+\operatorname{odds}_{\theta}\right]^{-1} \\
& {\left[1+\left(\operatorname{odds}_{\theta}\right)\left(1+\operatorname{odds}_{\theta}\right)\left(\operatorname{odds}_{\phi}\right)\right]^{-1}}
\end{aligned}
$$

The odds for a case to be reported in a medical system with a lag is Equation 6a,b:

$$
\operatorname{odds}_{\phi, \theta}=\frac{\operatorname{Pr}[\mathrm{Y} \geq 1]}{\operatorname{Pr}[\mathrm{Y}=0]} \approx\left(\operatorname{odds}_{\theta}\right) \mathrm{a}_{\phi, \theta}
$$

Where:

$$
\mathrm{a}_{\phi, \theta} \approx 1+\phi\left(1+\operatorname{odds}_{\theta}\right)^{2}
$$

Signifies an impact of "odds of quickening" on lag. A Taylorization is used to obtain (6a) and it is:

$$
\mathrm{f}(\phi, \theta) \approx \mathrm{f}(\phi=0, \theta)+\phi\left[\partial_{\phi=0} \mathrm{f}(\phi, \theta)\right]
$$

where, $\left.\partial_{\phi=0} \mathrm{f}(\phi, \theta)\right]$ is the derivative of a function $\mathrm{f}(\phi=\theta)$ ] evaluated at $\phi=0$. Now, statistical properties of the OGOD are discussed. First, the mean is derived. That is Equation 7:

$$
\begin{aligned}
& \mu_{\phi, \theta}=\mathrm{E}(\mathrm{Y} \mid \phi, \theta) \\
& {\left[(1-\theta)^{2} \theta \sum_{\mathrm{y}=0}^{\infty} \mathrm{y} \theta^{\mathrm{y}-1}+\left(\frac{\phi}{1-\phi}\right)(1-\theta)\right.} \\
& =\frac{\left.\left\{\theta^{2} \sum_{\mathrm{y}=0}^{\infty} \mathrm{y}(\mathrm{y}-1) \theta^{\mathrm{y}-2}+\theta \sum_{\mathrm{y}=0}^{\infty} \mathrm{y} \theta^{\mathrm{y}-1}\right\}\right]}{\left[(1-\theta)+\left(\frac{\phi}{1-\phi}\right)\left(\frac{\theta}{1-\theta}\right)\right]} \\
& =\mu_{\theta}\left[1+\frac{\left(\operatorname{odds}_{\phi}\right)\left(1+\left(\operatorname{odds}_{\theta}\right)^{2}\right)}{\left\{1+\left(\operatorname{odds}_{\phi}\right)\left(\operatorname{odds}_{\theta}\right)\left(1+\operatorname{odds}_{\theta}\right)\right\}}\right] \\
& \approx\left[\operatorname{odds}_{\theta}\right]\left[1+\phi\left(1+\operatorname{odds}_{\theta}\right)^{2}\right] .
\end{aligned}
$$

Interestingly, the mean in an absence of "odds of quickening" to report delayed cases (that is, odds ${ }_{\phi}=0$ or equivalently,

$\phi$

$=$

$0)$ 
$\mu_{\phi=0, \theta}=\mathrm{E}(\mathrm{Y} \mid \phi=0, \theta)=\mu_{\theta}=\frac{\theta}{1-\theta}=\operatorname{odds}_{\theta}$. Hence, the mean, (7) is viewed as $\mu_{\phi, \theta}=\mu_{\theta} \mathrm{a}_{\text {mean }, \phi, \theta}$ where Equation 8:

$$
\begin{aligned}
& \mathrm{a}_{\text {mean }, \phi, \theta} \\
& =\left[1+\frac{\left.\left(\operatorname{odds}_{\phi}\right)\left(1+\operatorname{odds}_{\theta}\right)^{2}\right)}{\left\{1+\left(\operatorname{odds}_{\phi}\right)\left(\operatorname{odds}_{\theta}\right)\left(1+\operatorname{odds}_{\theta}\right)\right\}}\right] \\
& \approx \operatorname{odds}_{\phi, \theta} \\
& \approx\left[\operatorname{odds}_{\theta}\right]\left[1+\phi\left(1+\operatorname{odds}_{\theta}\right)^{2}\right]
\end{aligned}
$$

Is an impact of "odds of quickening" on mean. The impact values could be compared over the years to get a clue on how the delayed reporting has improved. This knowledge is useful to health administrators. It is easy to see that Equation 9a-d:

$$
\begin{aligned}
& (1-\theta)^{-1}=1+\theta+\theta^{2}+\ldots \ldots . . .=\sum_{\mathrm{y}=0}^{\infty} \theta^{\mathrm{y}} \\
& (1-\theta)^{-2}=1+2 \theta+3 \theta^{2}+. .=\frac{1}{\theta} \sum_{\mathrm{y}=0}^{\infty} \mathrm{y} \theta^{\mathrm{y}} \\
& 2 \theta^{2}(1-\theta)^{-3}+\theta(1-\theta)^{-2}=\sum_{\mathrm{y}=0}^{\infty} \mathrm{y}^{2} \theta^{\mathrm{y}} \\
& 6 \theta^{3}(1-\theta)^{-4}+6 \theta^{2}(1-\theta)^{-3}+\theta(1-\theta)^{-2} \\
& =\sum_{\mathrm{y}=0}^{\infty} \mathrm{y}^{3} \theta^{\mathrm{y}}
\end{aligned}
$$

The dispersion $\sigma_{\phi, \theta}^{2}$ of the OGOD is obtained using the relations in (9a through 9d). After algebraic simplifications, it turns out to be Equation 10:

$$
\sigma_{\phi, \theta}^{2} \approx\left(\operatorname{odds}_{\theta}\right)\left(1+\operatorname{odds}_{\theta}\right)\left|1-\phi\left(\operatorname{odds}_{\theta}\right)\right|
$$

In the absence of "odds of quickening" to report (that is, $\phi=0)$, expression (10) yields dispersion $\sigma_{\phi=0, \theta}^{2}=\left(\operatorname{odds}_{\theta}\right)\left(1+\operatorname{odds}_{\theta}\right)$ of the geometric distribution (1). Hence, dispersion (10) is viewed as $\sigma_{\phi, \theta}^{2} \approx \sigma_{\phi=0, \theta}^{2} \mathrm{a}_{\text {variance, } \phi, \theta}$ where Equation 11:

$$
\mathrm{a}_{\text {dispersion, } \phi, \theta}=\left|1-\phi\left(\operatorname{odds}_{\theta}\right)\right|
$$

Portrays an impact of "odds of quickening" to report on dispersion. Next, the survival function:

$$
\overline{\mathrm{G}}_{\phi, \theta}(\mathrm{r}+1)=\operatorname{Pr}[\mathrm{Y} \geq \mathrm{r}+1 \mid \phi, \theta]
$$

For the OGOD (3) is derived in terms of the Fdistribution. The table for F-distribution is popularly available. The incomplete beta function in (12) is indeed F-distribution. It is easy to see that Equation 12:

$$
\begin{aligned}
& \sum_{y=r+1}^{\infty}(1-\theta) \theta^{y}=(r+1) \int_{1-\theta}^{1}(1-y)^{r} d y \\
& =\left(\frac{\operatorname{odds}_{\theta}}{1+\operatorname{odds}_{\theta}}\right)^{r+1}=\operatorname{IB}_{\theta}(r+1,1) \\
& =\operatorname{Pr}\left[F_{2(r+1), 2} \leq \frac{\left(\operatorname{odds}_{\theta}\right)}{(r+1)}\right]
\end{aligned}
$$

Hence, the survival function is Equation13:

$\overline{\mathrm{G}}_{\phi, \theta}(\mathrm{r}+1)=\operatorname{Pr}[\mathrm{Y} \geq \mathrm{r}+1 \mid \phi, \theta]$

$=\sum_{\mathrm{y}=\mathrm{r}+1}^{\infty} \mathrm{p}(\mathrm{y} \mid \phi, \theta)$

$=\frac{\left[1+\left(1+\operatorname{odds}_{\theta}\right) \operatorname{odds}_{\phi} \mathrm{y}\right]\left(\operatorname{odds}_{\theta}\right)^{\mathrm{y}}}{\left[1+\operatorname{odds}_{\theta}\left(1+\operatorname{odds}_{\theta}\right) \operatorname{odds}_{\phi}\right]\left(1+\operatorname{odds}_{\theta}\right)^{\mathrm{y}+1}}$

$\approx \operatorname{Pr}\left[\mathrm{F}_{2(\mathrm{r}+1), 2} \leq \frac{\left(\operatorname{odds}_{\theta}\right)}{(\mathrm{r}+1)}\right]+\phi\left(1+\operatorname{odds}_{\theta}\right)$

$\left\{(\mathrm{r}+1) \operatorname{Pr}\left[\mathrm{F}_{2 \mathrm{r}, 2} \leq \frac{\left(\mathrm{odds}_{\theta}\right)}{\mathrm{r}}\right]\right.$

$\left.-\mu_{\theta} \operatorname{Pr}\left[\mathrm{F}_{2(\mathrm{r}+1), 2} \leq \frac{\left(\operatorname{odds}_{\theta}\right)}{(\mathrm{r}+1)}\right]\right\}$.

The survival function (13) could be viewed as $\overline{\mathrm{G}}_{\phi, \theta}(\mathrm{r}+1)=\overline{\mathrm{G}}_{\phi=0, \theta}(\mathrm{r}+1) \mathrm{a}_{\text {survival }, \phi \theta}$ where an impact of "odds of quickening" to report on survival function is Equation 14:

$$
\begin{aligned}
& \mathrm{a}_{\text {survival }, \phi, \theta}=1+\phi\left(1+\operatorname{odds}_{\theta}\right) \\
& \left\{(\mathrm{r}+1) \frac{\operatorname{Pr}\left[\mathrm{F}_{2 \mathrm{r}, 2} \leq \frac{\left(\mathrm{odds}_{\theta}\right)}{\mathrm{r}}\right]}{\operatorname{Pr}\left[\mathrm{F}_{2(\mathrm{r}+1), 2} \leq \frac{\left(\mathrm{odds}_{\theta}\right)}{(\mathrm{r}+1)}\right]}-\left(\operatorname{odds}_{\theta}\right)\right\}
\end{aligned}
$$

By substituting $r=0$ in (13), it yields the chance for a lag to exist. That is Equation 15:

$$
\begin{aligned}
& \overline{\mathrm{G}}_{\phi, \theta}(1)=\operatorname{Pr}[\mathrm{Y} \geq 1 \mid \phi, \theta] \approx \operatorname{Pr}\left[\mathrm{F}_{2,2} \leq\left(\operatorname{odds}_{\theta}\right)\right] \\
& +\phi\left(1+\operatorname{odds}_{\theta}\right)\left\{1-\left(\operatorname{odds}_{\theta}\right) \operatorname{Pr}\left[\mathrm{F}_{2,2} \leq\left(\operatorname{odds}_{\theta}\right)\right]\right\}
\end{aligned}
$$

In the absence of "odds of quickening" to report (that is, $\phi=0$ ), expression (15) reduces to Equation 16:

$$
\begin{aligned}
& \overline{\mathrm{G}}_{\phi=0, \theta}(1)=\operatorname{Pr}[\mathrm{Y} \geq 1 \mid \phi=0, \theta] \\
& \approx \operatorname{Pr}\left[\mathrm{F}_{2,2} \leq\left(\operatorname{odds}_{\theta}\right)\right]
\end{aligned}
$$


So, what is an impact of "odds of quickening" to report on medical system to be "busy"? This is implied in the relation $\overline{\mathrm{G}}_{\phi, \theta}(1)=\overline{\mathrm{G}}_{\phi=0, \theta}(1) \mathrm{a}_{\text {busy }, \phi, \theta}$ where the level of busy is Equation 17:

$$
\begin{aligned}
& \mathrm{a}_{\text {bus }, \phi, \theta}(1)=1+\phi\left\{1+\left(\operatorname{odds}_{\theta}\right)\right\} \\
& \left.\left(\left\{\operatorname{Pr}\left[\mathrm{F}_{2,2} \leq\left(\operatorname{odds}_{\theta}\right)\right]\right\}^{-1}-\left(\operatorname{odds}_{\theta}\right)\right\}\right)
\end{aligned}
$$

and it portrays an impact of "odds of quickening" to report on busy. Now, a discussion on how much a memory is created in a reporting medical system because of the lag. Recall that the geometric distribution (1) is known to possess a memory less property as shown in (2). From OGOD (3), note that:

$$
\begin{aligned}
& \operatorname{Pr}[(\mathrm{Y} \geq \mathrm{m}+\mathrm{t} \mid \mathrm{Y} \geq \mathrm{m}) \mid \phi, \theta] \\
& =\frac{\operatorname{Pr}[(\mathrm{Y} \geq \mathrm{m}+\mathrm{t} \cap \mathrm{Y} \geq \mathrm{m}) \mid \phi, \theta]}{\operatorname{Pr}[\mathrm{Y} \geq \mathrm{m} \mid \phi, \theta]} \\
& =\mathrm{m}_{\phi, \theta} \operatorname{Pr}[(\mathrm{Y} \geq \mathrm{t} \| \phi, \theta]
\end{aligned}
$$

where a reporting medical-system's memory is Equation 18:

$$
\begin{aligned}
& {\left[1+\left(\operatorname{odds}_{\phi}\right)\left\{1+\left(\operatorname{odds}_{\theta}\right)\right\}\right.} \\
& \left.\left\{\mathrm{m}+\mathrm{t}+\left(\text { odds }_{\theta}\right)\right\}\right] \\
& \mathrm{m}_{\phi, \theta}=\frac{\left[1+\left(\operatorname{odds}_{\phi}\right)\left(\operatorname{odds}_{\theta}\right)\left\{1+\left(\operatorname{odds}_{\theta}\right)\right\}\right]}{\left[1+\left(\operatorname{odds}_{\phi}\right)\left\{1+\left(\operatorname{odds}_{\theta}\right)\right\}\right.} \\
& \left.\left\{\mathrm{m}+\left(\operatorname{odds}_{\theta}\right)\right\}\right] \\
& {\left[1+\left(\operatorname{odds}_{\phi}\right)\left\{1+\left(\operatorname{odds}_{\theta}\right)\right\}\right.} \\
& \left.\left\{\mathrm{t}+\left(\operatorname{odds}_{\theta}\right)\right\}\right] \\
& \left\{\operatorname{Pr}\left[\mathrm{F}_{2(\mathrm{~m}+\mathrm{t}), 2} \leq \frac{\left(\mathrm{odds}_{\theta}\right)}{(\mathrm{m}+\mathrm{t})}\right]\right. \\
& +\phi\left(1+\left(\operatorname{odds}_{\theta}\right)\right)\left\{(\mathrm{m}+\mathrm{t}) \operatorname{Pr}\left[\mathrm{F}_{2 \mathrm{r}, 2} \leq \frac{\left(\mathrm{odds}_{\theta}\right)}{\mathrm{m}+\mathrm{t}-1}\right]\right. \\
& \mathrm{m}_{\phi, \theta}=\frac{\left.-\left(\operatorname{odds}_{\theta}\right) \operatorname{Pr}\left[\mathrm{F}_{2(\mathrm{~m}+\mathrm{t}), 2} \leq \frac{\left(\operatorname{odds}_{\theta}\right)}{\mathrm{m}+\mathrm{t}}\right]\right\}}{\left\{\operatorname{Pr}\left[\mathrm{F}_{2 \mathrm{~m}, 2} \leq \frac{\left(\operatorname{odds}_{\theta}\right)}{\mathrm{m}}\right]+\phi\left\{1+\left(\operatorname{odds}_{\theta}\right)\right\}\right.} \\
& \left\{\mathrm{mPr}\left[\mathrm{F}_{2 \mathrm{r}, 2} \leq \frac{\left(\mathrm{odds}_{\theta}\right)}{\mathrm{m}-1}\right]\right. \\
& \left.-\mu_{\theta} \operatorname{Pr}\left[\mathrm{F}_{2 \mathrm{~m}, 2} \leq \frac{\left(\mathrm{odds}_{\theta}\right)}{\mathrm{m}}\right]\right\} \\
& \left\{\operatorname{Pr}\left[\mathrm{F}_{2 \mathrm{~m}, 2} \leq \frac{\left(\text { odds }_{\theta}\right)}{\mathrm{t}}\right]\right. \\
& +\phi\left\{1+\left(\operatorname{odds}_{\theta}\right)\right\}\left\{\mathrm{t} \operatorname{Pr}\left[\mathrm{F}_{2 \mathrm{r}, 2} \leq \frac{\left(\operatorname{odds}_{\theta}\right)}{\mathrm{t}-1}\right]\right. \\
& \left.-\left(\operatorname{odds}_{\theta}\right) \operatorname{Pr}\left[\mathrm{F}_{2 \mathrm{t}, 2} \leq \frac{\left(\text { odds }_{\theta}\right)}{\mathrm{t}}\right]\right\}
\end{aligned}
$$

In the absence of "odds of quickening" to report (that is, $\phi=0$ or $\operatorname{odds}_{\phi}=0$ ), expression (18) reduces to baseline value one, confirming the memory less property as stated in (2) for geometric distribution (1). Hence, a theorem is stated.

\section{Theorem 1:}

The chance mechanism which is governed by the oscillating geometric odds distribution (3) has a finite memory $\mathrm{m}_{\phi, \theta}$ in (18).

Now, the Maximum Likelihood Estimate (MLE) of the parameters $\phi$ and $\theta$ are obtained. A reason for choosing the MLE is that it is invariant. The MLE helps to perform a data analysis. Consider a random sample $\mathrm{y}_{1}$, $\mathrm{y}_{2}, \mathrm{y}_{3}, \ldots ., \mathrm{y}_{\mathrm{n}}$ from OGOD (3). Then, the log likelihood function is Equation 19:

$$
\begin{aligned}
& \ln \mathrm{L}(\phi, \theta)=-\mathrm{n} \ln \left[1-\theta+\operatorname{odds}_{\phi} \operatorname{odds} \theta\right] \\
& +\sum_{\mathrm{i}=1}^{\mathrm{n}} \ln \left[\left\{(1-\theta)^{2}+\operatorname{odds}_{\phi}(1-\theta) \mathrm{y}_{\mathrm{i}}\right\} \theta^{\mathrm{y}_{\mathrm{i}}}\right] \\
& \approx-\mathrm{n} \ln \left\{1+\left(\operatorname{odds}_{\theta}\right)\right\}+\mathrm{n} \phi\left(\operatorname{odds}_{\theta}\right)\left\{1+\left(\operatorname{odds}_{\theta}\right)\right\} \\
& +\mathrm{n} \overline{\mathrm{y}} \ln \left\{\frac{\left(\operatorname{odds}_{\theta}\right)}{1+\left(\operatorname{odds}_{\theta}\right)}\right\}+\mathrm{n} \phi \overline{\mathrm{y}}\left\{1+\left(\operatorname{odds}_{\theta}\right)\right\}
\end{aligned}
$$

The MLE $\hat{\phi}_{\text {mle }}$ and $\hat{\theta}_{\text {mle }}$ are the solutions of the score functions $\quad \partial_{\phi} \ln \mathrm{L}\left(\mathrm{y}_{1}, \mathrm{y}_{2}, \mathrm{y}_{3}, \ldots ., \mathrm{y}_{\mathrm{n}}, \theta, \phi\right)=0 \quad$ and $\partial_{\theta} \ln \mathrm{L}\left(\mathrm{y}_{1}, \mathrm{y}_{2}, \mathrm{y}_{3}, \ldots, \mathrm{y}_{\mathrm{n}}, \theta, \phi\right)=0$. Both score functions are nonlinear. The non-linearity is eased by their Taylor's series expansion. They result in the MLEs in (20) and (21) after algebraic simplifications. They are Equation 20 and 21:

$\hat{\phi}_{\mathrm{mle}} \approx \frac{\left|\overline{\mathrm{y}}(1+\overline{\mathrm{y}})-\mathrm{s}_{\mathrm{y}}^{2}\right|}{\overline{\mathrm{y}}+\left|\overline{\mathrm{y}}(1+\overline{\mathrm{y}})-\mathrm{s}_{\mathrm{y}}^{2}\right|}$

And:

$$
\hat{\theta}_{\text {mle, } \hat{\phi}_{\text {mle }}} \approx\left(1-\frac{\hat{\phi}_{\text {mle }} \bar{y}}{1+\bar{y}}\right) \frac{\bar{y}}{(1+\bar{y})}
$$

In the absence of "odds of quickening" to report, note that $\bar{y}(1+\bar{y}) \rightarrow s_{y}^{2}$ and expression (21) reduces to $\hat{\theta}_{\text {mle }, \hat{\phi}_{\text {mle }}=0}=\frac{\bar{y}}{(1+\bar{y})}$ pertaining to geometric distribution (1). In other words, geometric distribution (1) possesses a balance, $s_{y}^{2}=\bar{y}(1+\bar{y})$ between the sample variance $s_{y}^{2}$ and the quadratic expression $\bar{y}(1+\bar{y})$. This property is named 
"dispersion balance" and it exists in the absence of "odds of quickening" to report. Otherwise, there exists either "dispersion underbalance" with $\mathrm{s}_{\mathrm{y}}^{2}<\overline{\mathrm{y}}(1+\overline{\mathrm{y}})$ or "dispersion overbalance" with $\mathrm{s}_{\mathrm{y}}^{2}>\overline{\mathrm{y}}(1+\overline{\mathrm{y}})$ as a characteristic property of OGOD (3). The statistics community has been debating about under or over dispersion in data. However, the MLE of the mean in (7) is Equation 22:

$$
\begin{aligned}
& \hat{\mu}_{\hat{\phi}_{\text {mle }}, \theta} \\
& \approx\left(\frac{1-\hat{\phi}_{\text {mle }} \frac{\bar{y}}{1+\bar{y}}}{1+\hat{\phi}_{\text {mle }} \frac{\overline{\mathrm{y}}^{2}}{1+\bar{y}}}\right)\left(1+\frac{\hat{\phi}_{\text {mle }}[1+\bar{y}]^{2}}{\left[1+\hat{\phi}_{\text {mle }} \frac{\bar{y}^{2}}{1+\bar{y}}\right]^{2}}\right) \bar{y}
\end{aligned}
$$

which reduces to $\hat{\mu}_{\hat{\phi}_{\text {mle }}=0, \theta}=\bar{y}$ when $\quad \hat{\phi}_{\text {mle }} \rightarrow 0$ of the geometric distribution as a particular case in the absence of "odds of quickening" to report.

A health administrator is interested in a "ratio" $\mathrm{R}=\frac{\mathrm{Y}}{\mathrm{T}-\mathrm{Y}}>\mathrm{m}$ where $\mathrm{m}$ and $\mathrm{T}$ are respectively $\mathrm{a}$ specified threshold level and a total number of reported cases in a year. The ratio is the odds of the number of reported versus unreported number cases in a year. The epidemiologists are fond of this kind of odds. To make a probability assessment about the odds, the expected and variance values of $\mathrm{R}$ are needed. To find them, the formulas Equation 23a,b:

$$
\begin{aligned}
& E\left(\frac{W}{V}\right)=\frac{E_{w}}{E_{v}}\left(1+\frac{V_{v}}{E_{v}^{2}}-\frac{2 \operatorname{cov}[W, V]}{E_{w} E_{v}}\right) \\
& \operatorname{Var}\left(\frac{W}{V}\right) \\
& =\frac{E_{w}^{2}}{E_{v}^{2}}\left(\frac{V_{w}}{E_{w}^{2}}+\frac{V_{v}}{E_{v}^{2}}-\frac{2 \operatorname{cov}[W, V]}{E_{w} E_{v}}\right)
\end{aligned}
$$

are used (Stuart and Ord (1994) for details), where $E_{j}$ and $\mathrm{V}_{\mathrm{j}}$ denote the mean and variance respectively of $\mathrm{j}=\mathrm{W}$ or V. That is Equation 24 and 25:

$$
\begin{aligned}
& \mathrm{E}(\mathfrak{R})=\mathrm{E}\left(\frac{\mathrm{Y}}{\mathrm{T}-\mathrm{Y}}\right)=\frac{\mu_{\phi, \theta}}{\left[\mathrm{T}-\mu_{\phi, \theta}\right]}\left(1+\frac{\sigma_{\phi, \theta}^{2}}{\left[\mathrm{~T}-\mu_{\phi, \theta}\right]^{2}}\right. \\
& \left.-\frac{2 \operatorname{cov}[\mathrm{Y}, \mathrm{T}-\mathrm{Y}]}{\mu_{\phi, \theta}\left[\mathrm{T}-\mu_{\phi, \theta}\right]}\right) \\
& =\frac{\mu_{\phi, \theta}}{\left[\mathrm{T}-\mu_{\phi, \theta}\right]}\left(1+\frac{\sigma_{\phi, \theta}^{2}\left[2 \mathrm{~T}-\mu_{\phi, \theta}\right]}{\mu_{\phi, \theta}\left[\mathrm{T}-\mu_{\phi, \theta}\right]^{2}}\right)
\end{aligned}
$$

And:

$$
\operatorname{Var}(\Re)=\operatorname{Var}\left(\frac{\mathrm{Y}}{\mathrm{T}-\mathrm{Y}}\right)=\frac{\mathrm{T}^{2} \sigma_{\phi, \theta}^{2}}{\left[\mathrm{~T}-\mu_{\phi, \theta}\right]^{4}}
$$

Hence, $\operatorname{Pr}[\mathfrak{R}>\mathrm{m}] \approx 1-\Phi_{\mathrm{z}}\left(\frac{\mathrm{m}-\mathrm{E}\left[\hat{\mathfrak{R}}_{\text {mle }}\right]}{\sqrt{\operatorname{Var}\left[\hat{\mathfrak{R}}_{\text {mle }}\right]}}\right)$ where $\Phi_{\mathrm{z}}(\mathrm{p})$ is the cumulative area under the standard normal distribution up to a percentile $p$, the MLEs $E\left[\hat{\mathfrak{R}}_{\text {mle }}\right]$ and $\operatorname{Var}\left[\hat{\mathfrak{R}}_{\text {mle }}\right]$ are computed using (23), (24), (25), (20) and (21).

A healthcare administrator often ponders over a question: Do the data give a clue about the absence or insignificant level of "odds of quickening"? An answer to this question requires a hypothesis testing methodology. For this purpose, the Wald (1943) likelihood ratio concept is invoked in this article. According to Wald's concept, to test the null hypothesis $\mathrm{H}_{\mathrm{o}}: \phi=0$ against an alternative hypothesis $\mathrm{H}_{1}: \phi=\phi^{*} \neq 0$, the log-likelihood ratio is Equation 26:

$$
\begin{aligned}
& -\ln \Lambda_{\phi^{*}}=\ln \mathrm{L}\left(\hat{\phi}_{\mathrm{mle}}, \hat{\theta}_{\hat{\phi}^{\mathrm{mle}}}\right)-\ln \mathrm{L}\left(\phi^{*}, \hat{\theta}_{\phi^{*}, \text { mle }}\right) \\
& \approx \mathrm{n}\left[\left\{\overline{\mathrm{y}} \ln \hat{\theta}_{\hat{\phi}, \mathrm{mle}}+\ln \left(1-\hat{\theta}_{\hat{\phi}, \mathrm{mle}}\right)\right\}-\hat{\phi}_{\mathrm{mle}}\left\{\frac{1-\overline{\mathrm{y}}}{1-\hat{\theta}_{\hat{\phi}, \mathrm{mle}}}\right\}\right. \\
& \left.-\left\{\overline{\mathrm{y}} \ln \hat{\theta}_{\hat{\phi}^{*}, \mathrm{mle}}+\ln \left(1-\hat{\theta}_{\hat{\phi}^{*}, \mathrm{mle}}\right)\right\}-\phi^{*}\left\{\frac{1-\overline{\mathrm{y}}}{1-\hat{\theta}_{\phi^{*}, \mathrm{mle}}}\right\}\right]
\end{aligned}
$$

Under the null hypothesis, $\hat{\theta}_{\text {mle }, \phi=0}=\frac{\bar{y}}{(1+\bar{y})}$, $\hat{\mu}_{\hat{\theta}_{\mathrm{mle}, \phi=0}}=\frac{\hat{\theta}_{\mathrm{mle}, \phi=0}}{1-\hat{\theta}_{\text {mle }, \phi=0}}=\bar{y}$ and hence Equation 27:

$$
\begin{aligned}
& -\ln \Lambda_{\phi=0} \\
& \approx \mathrm{n}\left[\hat{\phi}_{\text {mle }}\left\{\frac{1-\bar{y}}{1-\hat{\theta}_{\hat{\phi}, \mathrm{mle}}}\right\}-\left\{\overline{\mathrm{y}} \ln \left(\frac{\hat{\theta}_{\hat{\phi}, \mathrm{mle}}(1+\overline{\mathrm{y}})}{\overline{\mathrm{y}}}\right)\right\}\right. \\
& \left.+\ln \left\{\left(1-\hat{\theta}_{\hat{\phi}, \mathrm{mle}}\right)(1+\overline{\mathrm{y}})\right\}\right]
\end{aligned}
$$

Which follows a non-central chi-squared distribution with one degrees of freedom (df) and the non-centrality parameter $\hat{\delta}_{\phi=0}=\hat{\phi}_{\text {mle }} / \operatorname{var}\left(\hat{\phi}_{\text {mle }}\right)$, where $\operatorname{var}\left(\hat{\phi}_{\text {mle }}\right)$ is a diagonal element in the inverse of the variancecovariance matrix of the MLEs. Stuart and Ord (1994) for definition and properties of the non-central chi 
squared distribution. Recall that the variance-covariance matrix of the MLE of the parameters is the inverse of the information

$$
\begin{array}{ll}
\mathrm{I}=\left[\begin{array}{ll}
\mathrm{a} & \mathrm{b} \\
\mathrm{b} & \mathrm{c}
\end{array}\right]=\left[\begin{array}{ll}
-\mathrm{E}\left(\partial_{\phi \phi}^{2} \ln \mathrm{L}\right) & -\mathrm{E}\left(\partial_{\phi \theta}^{2} \ln \mathrm{L}\right) \\
-\mathrm{E}\left(\partial_{\phi \theta}^{2} \ln \mathrm{L}\right) & -\mathrm{E}\left(\partial_{\theta \theta}^{2} \ln \mathrm{L}\right)
\end{array}\right], & \text { with } \\
\mathrm{a}=-\mathrm{E}\left(\partial_{\phi \phi}^{2} \ln \mathrm{L}\right)=0, & \text { and } \\
\mathrm{b}=-\mathrm{E}\left(\partial_{\phi \theta}^{2} \ln \mathrm{L}\right) \approx \mathrm{n}\left[2\left(\frac{\theta}{1-\theta}\right)+1-\mu_{\phi, \theta}\right] /(1-\theta)^{2} & \mathrm{n}\left[\frac{\mu_{\phi, \theta}}{\theta^{2}}+\frac{1}{(1-\theta)^{2}}\right. \\
\mathrm{c}=-\mathrm{E}\left(\partial_{\theta \theta}^{2} \ln \mathrm{L}\right) \approx & \\
\left.-\frac{2 \phi}{(1-\theta)^{3}}\left\{\mu_{\phi, \theta}-2-3\left(\frac{\theta}{1-\theta}\right)\right\}\right] . &
\end{array}
$$

The determinant of the matrix I is $D=|I|=-b^{2}$ and $\operatorname{var}\left(\hat{\phi}_{\mathrm{mle}}\right)=\mathrm{b}^{-1}$. Hence:

$$
\begin{aligned}
& \hat{\delta}_{\phi=0}=\hat{\phi}_{\mathrm{mle}} / \operatorname{var}\left(\hat{\phi}_{\mathrm{mle}}\right) \\
& \approx \frac{\left[\frac{\left|\overline{\mathrm{y}}(1-\overline{\mathrm{y}})-\mathrm{s}_{\mathrm{y}}^{2}\right|}{\overline{\mathrm{y}}+\left|\overline{\mathrm{y}}(1-\overline{\mathrm{y}})-\mathrm{s}_{\mathrm{y}}^{2}\right|}\right]\left(1-\hat{\theta}_{\mathrm{mle}, \hat{\phi}_{\mathrm{mle}}}\right)^{2}}{\mathrm{n}\left[2\left(\frac{\hat{\theta}_{\mathrm{mle}, \hat{\phi}_{\mathrm{mle}}}}{1-\hat{\theta}_{\mathrm{mle}, \hat{\phi}_{\mathrm{mle}}}}\right)+1-\hat{\mu}_{\hat{\phi}_{\mathrm{mle}}, \hat{,}_{\hat{\phi}, \mathrm{mle}}}\right]}
\end{aligned}
$$

The non-central chi squared distribution with one df and non-centrality parameter $\delta$ approximately follows $\left(1+\frac{\delta}{1+\delta}\right)$ times a central chi squared distribution with $\frac{(1+\delta)^{2}}{(1+2 \delta)}$ df (Stuart and Ord (1994) for details). This means that the null hypothesis $\mathrm{H}_{\mathrm{o}}: \phi=0$ will be rejected in favor of an alternative hypothesis $\mathrm{H}_{\mathrm{o}}: \phi=\phi^{*} \neq 0$ when:

$$
-\ln \Lambda_{\phi=0}>\left(1+\frac{\hat{\delta}_{\phi=0}}{1+\hat{\delta}_{\phi=0}}\right) \chi_{\frac{\left(1+\hat{\delta}_{\phi=0}\right)^{2}}{\left(1+2 \hat{\delta}_{\phi=0}\right)}}^{2} \mathrm{df}, \alpha
$$

where the right side is the critical value based on the $100(1-\alpha)^{\text {th }}$ percentile of the central chi squared distribution with $\frac{\left(1+\hat{\delta}_{\phi=0}\right)^{2}}{\left(1+2 \hat{\delta}_{\phi=0}\right)}$ df and a significance level $\alpha \in(0,1)$. The p-value for rejecting the null hypothesis in favor of an alternative hypothesis is Equation 28:

$$
\mathrm{p}-\text { value }=\operatorname{Pr}\left[\chi_{\frac{\left(1+\hat{\delta}_{\phi=0}\right)^{2}}{\left(1+2 \hat{\delta}_{\phi=0}\right)}}^{2}<\frac{-\ln \Lambda_{\phi=0}}{\left(1+\frac{\hat{\delta}_{\phi=0}}{1+\hat{\delta}_{\phi=0}}\right)}\right]
$$

The statistical power of the test statistic (28) is now examined with a selection of a specific attainable value for $\phi^{*}$ in the alternative hypothesis. The statistical power is the probability of accepting a true alternative hypothesis $\mathrm{H}_{1}: \phi=\phi^{*} \neq 0$. Under an alternative hypothesis, the minus log likelihood ratio follows a noncentral chi-squared distribution with one df and noncentrality parameter:

$$
\begin{aligned}
& \hat{\delta}_{j^{*}}=\frac{\left(\hat{\mathrm{j}}_{\mathrm{mle}}-\mathrm{j}^{*}\right)}{\operatorname{var}\left(\hat{\mathrm{j}}_{\mathrm{mle}}\right)} \\
& » \frac{\left[\frac{\left|\bar{y}(1-\bar{y})-s_{y}^{2}\right|}{\bar{y}+\left|\bar{y}(1-\bar{y})-s_{y}^{2}\right|}-j^{*}\right]\left(1-\hat{\theta}_{m l e, \hat{j}_{m l e}}\right)^{2}}{n\left[2\left(\frac{\hat{\theta}_{m l e, \hat{j}_{m l e}}}{1-\hat{\theta}_{m l e, \hat{j}_{m l e}}}\right)+1-\hat{\mu}_{\hat{j}_{m l e}, \hat{\theta}_{m l e}, \hat{j}_{m l e}}\right]}
\end{aligned}
$$

This non-central chi squared distribution with one df and non-centrality parameter $\hat{\delta}_{\phi^{*}}$ is approximately $\left(1+\frac{\hat{\delta}_{\phi^{*}}}{1+\hat{\delta}_{\phi^{*}}}\right)$ times a central chi squared score with $\frac{\left(1+\hat{\delta}_{\phi^{*}}\right)^{2}}{\left(1+2 \hat{\delta}_{\phi^{*}}\right)}$ df. That is Equation 29:

$$
\begin{aligned}
& \text { Power }=
\end{aligned}
$$

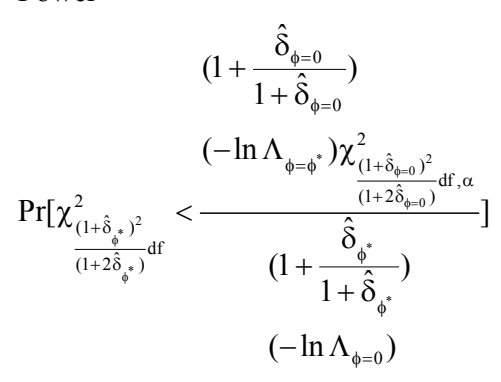

\subsection{Reporting Aids Cases for Illustration}

The results of the section 2 are illustrated using delayed reporting of AIDS cases in Hay and Wolak (1994) as quoted in Table 1. The number, $n$ of quarters in their delayed reporting during 1982 through 1990 ranged from 2 to 17 . The Maximum Likelihood Estimates (MLE) of the parameters is displayed in Table 2. The high value of $\hat{\phi}_{\text {mle }}$ in its domain $[0,1]$ is indicative of the existence of "odds of quickening" to report. The estimate of the probability $\hat{\theta}_{\text {mle }}$ for a case to be delayed 
without reporting in its occurrence period itself is high in its domain $[0,1]$ only in the beginning during 1982 but it has been decreasing over the years. The p-value for the null hypothesis $\mathrm{H}_{\mathrm{o}}: \phi=0$ to be true is small enough to believe that "odds of quickening" to report indeed existed. The medical administrators had been quite consciously trying to quicken the reporting of already delayed cases. With the total, $\mathrm{T}$ number of AIDS cases, the power of accepting $\mathrm{H}_{1}: \phi^{*}=0.5$ using the given data is higher in a quarter during 1982 through 1990 (Table 2). The Fig. 1 suggests that the chance for reporting an AIDS case at a later quarter had been increasing over the years though the total number of AIDS cases grew according to Fig. 2. As can be seen in Fig. 3, the chance for majority of the AIDS cases get reported in the same quarter of its occurrence oscillated over the years but it became phenomenal in the later time period. The odds of reporting an AIDS case in the same quarter of its occurrence increased more in the beginning than in later period during years 1982-1990 due to "odds of quickening" to report, according to the Fig. 4. The Fig. 5 indicates that the impact of "odds of quickening" to report on busy medical system during years 1982-1990. Together, the $\operatorname{MLE} \hat{\theta}_{\text {mle, } \hat{\phi}_{\text {mle }}=0}=\frac{\bar{y}}{(1+\bar{y})}$ and $\operatorname{odds}_{\hat{\theta}_{\text {mle. } \hat{\phi}_{m l e}=0}}=\bar{y}$ portray the probability to report an AIDS case in the absence of "odds of quickening". Notice in Fig. 3 that those chances have been oscillating over the years during 1982 through 1990. The probability for an existence of "quickening" attitude to report a case is $\hat{\phi}_{\text {mle }}$ if the case was reported in the same quarter of its occurrence. The chance for reporting an AIDS case in the same quarter of its occurrence is $1-\hat{\theta}_{\text {mle, } \hat{\phi}_{\text {me }}}$ in the presence of "quickening odds" to report. The impact, $\mathrm{a}_{\phi, \theta}$ of "quickening odds" is displayed in Table 2. Their values suggest that the "quickening odds" changed over the years during 19821990. The impact, $a_{\text {mean, } \phi, \theta}$ of "quickening odds" on mean has been reducing over the years during 1982 through 1990 (Table 2). Likewise, the $a_{\text {dispersion, } \phi, \theta}$ captures the impact of "quickening odds" to report on dispersion (Table 2). According to their values, the impact has been increasing over the years during 1982 through 1990.

Table 1. Reported number of AIDS cases, Y in a quarter during 1989-1990 in USA

\begin{tabular}{|c|c|c|c|c|c|c|c|c|c|c|c|c|c|c|c|c|c|c|c|}
\hline Yr, Quarte & Q0 & Q1 & Q2 & Q3 & Q4 & Q5 & Q6 & Q7 & Q8 & Q9 & Q10 & Q1 1 & Q12 & Q13 & Q14 & Q15 & Q16+ & $\overline{\mathrm{y}}$ & $\mathrm{S}_{\mathrm{y}}$ \\
\hline 1982, Q1 & 31 & 49 & 32 & 10 & 5 & 10 & 5 & 2 & 4 & 0 & 2 & 0 & 0 & 0 & 0 & 0 & 35 & 10.88 & 15.56 \\
\hline $1982, \mathrm{Q} 2$ & 40 & 67 & 11 & 5 & 10 & 9 & 7 & 3 & 0 & 2 & 1 & 3 & 1 & 0 & 1 & 0 & 41 & 11.82 & 19.03 \\
\hline 1982, Q3 & 78 & 73 & 32 & 21 & 12 & 11 & 1 & 3 & 1 & 2 & 2 & 1 & 1 & 1 & 2 & 2 & 50 & 17.24 & 25.77 \\
\hline $1982, \mathrm{Q} 4$ & 96 & 129 & 30 & 33 & 17 & 5 & 2 & 3 & 1 & 0 & 2 & 3 & 1 & 0 & 0 & 1 & 58 & 22.41 & 37.93 \\
\hline 1983, Q1 & 134 & 177 & 68 & 34 & 14 & 12 & 4 & 7 & 3 & 4 & 3 & 4 & 2 & 1 & 2 & 0 & 67 & 31.53 & 51.91 \\
\hline $1983, \mathrm{Q} 2$ & 57 & 378 & 85 & 43 & 20 & 18 & 12 & 9 & 5 & 6 & 5 & 0 & 5 & 5 & 2 & 3 & 52 & 41.47 & 90.06 \\
\hline 1983, Q3 & 69 & 420 & 113 & 34 & 19 & 12 & 10 & 10 & 4 & 4 & 3 & 4 & 3 & 3 & 7 & 4 & 50 & 45.24 & 101.10 \\
\hline 1983, Q4 & 26 & 513 & 109 & 55 & 25 & 17 & 7 & 8 & 4 & 3 & 7 & 9 & 8 & 7 & 5 & 0 & 48 & 50.06 & 122.40 \\
\hline 1984, Q1 & 55 & 675 & 151 & 59 & 32 & 26 & 18 & 8 & 9 & 7 & 7 & 4 & 9 & 7 & 5 & 6 & 70 & 67.53 & 161.00 \\
\hline 1984, Q2 & 82 & 790 & 164 & 85 & 57 & 36 & 16 & 4 & 11 & 9 & 6 & 12 & 9 & 11 & 11 & 11 & 65 & 81.12 & 187.60 \\
\hline 1984, Q3 & 108 & 845 & 241 & 112 & 47 & 40 & 18 & 16 & 15 & 9 & 8 & 8 & 5 & 13 & 11 & 7 & 70 & 92.53 & 203.20 \\
\hline 1984, Q4 & 118 & 960 & 247 & 112 & 65 & 30 & 27 & 15 & 11 & 18 & 15 & 13 & 13 & 16 & 29 & 15 & 60 & 103.80 & 228.90 \\
\hline $1985, \mathrm{Q} 1$ & 146 & 1191 & 252 & 129 & 83 & 67 & 34 & 20 & 18 & 22 & 10 & 18 & 22 & 27 & 23 & 21 & 68 & 126.50 & 281.60 \\
\hline 1985, Q2 & 160 & 1454 & 292 & 143 & 93 & 58 & 48 & 35 & 24 & 20 & 29 & 46 & 33 & 31 & 22 & 27 & 62 & 151.60 & 342.90 \\
\hline 1985, Q3 & 152 & 1620 & 400 & 225 & 101 & 71 & 53 & 39 & 20 & 56 & 55 & 44 & 29 & 35 & 29 & 21 & 54 & 176.70 & 384.20 \\
\hline $1985, \mathrm{Q} 4$ & 97 & 1739 & 422 & 164 & 120 & 58 & 52 & 52 & 57 & 65 & 83 & 41 & 37 & 27 & 26 & 17 & 47 & 182.60 & 412.00 \\
\hline 1986, Q1 & 148 & 2046 & 406 & 218 & 107 & 118 & 56 & 7 & 135 & 102 & 81 & 49 & 53 & 40 & 27 & 30 & 53 & 222.10 & 478.80 \\
\hline 1986, Q2 & 562 & 2039 & 555 & 200 & 143 & 91 & 152 & 160 & 133 & 94 & 77 & 66 & 41 & 31 & 39 & 38 & 54 & 263.20 & 485.20 \\
\hline 1986, Q3 & 232 & 2444 & 532 & 275 & 148 & 196 & 229 & 165 & 123 & 80 & 62 & 58 & 36 & 42 & 39 & 31 & & 293.30 & 587.90 \\
\hline 1986, Q4 & 181 & 2441 & 763 & 290 & 240 & 282 & 183 & 143 & 101 & 82 & 67 & 35 & 38 & 50 & & & & 349.70 & 630.20 \\
\hline 1987, Q1 & 224 & 2981 & 673 & 408 & 370 & 353 & 224 & 185 & 99 & 128 & 85 & 85 & 78 & 56 & & & & 424.90 & 755.70 \\
\hline 1987, Q2 & 129 & 3260 & 897 & 592 & 426 & 272 & 156 & 125 & 138 & 121 & 91 & 96 & 74 & & & & & 493.40 & 866.00 \\
\hline 1987, Q3 & 96 & 3567 & 1207 & 569 & 374 & 227 & 195 & 138 & 102 & 118 & 117 & 85 & & & & & & 563.00 & 999.50 \\
\hline 1987, Q4 & 135 & 3847 & 1218 & 444 & 315 & 247 & 196 & 128 & 149 & 140 & 102 & & & & & & & 629.10 & 1114.00 \\
\hline $1988, \mathrm{Q} 1$ & 163 & 4401 & 1096 & 462 & 354 & 334 & 225 & 186 & 203 & 165 & & & & & & & & 756.00 & 1311.00 \\
\hline 1988, Q2 & 307 & 4608 & 968 & 500 & 372 & 284 & 222 & 231 & 182 & & & & & & & & & 853.00 & 1428.00 \\
\hline 1988, Q3 & 332 & 4521 & 1186 & 569 & 334 & 317 & 268 & 193 & & & & & & & & & & 959.30 & 1474.00 \\
\hline $1988, \mathrm{Q} 4$ & 256 & 4525 & 1327 & 487 & 375 & 387 & & & & & & & & & & & & 1089.00 & 1560.00 \\
\hline 1989, Q1 & 311 & 5016 & 1248 & 569 & 527 & 438 & & & & & & & & & & & & 1352.00 & 1825.00 \\
\hline 1989, Q2 & 342 & 5186 & 1370 & 814 & 512 & & & & & & & & & & & & & 1645.00 & 2018.00 \\
\hline 1989, Q3 & 349 & 5124 & 1515 & 830 & & & & & & & & & & & & & & 1955.00 & 2166.00 \\
\hline $1989, \mathrm{Q} 4$ & 192 & 4989 & 1745 & & & & & & & & & & & & & & & 2312.00 & 2453.00 \\
\hline 1989, Q33 & 276 & 5646 & & & & & & & & & & & & & & & & 2961.00 & 3797.00 \\
\hline
\end{tabular}


Ramalingam Shanmugam / International Journal of Research in Nursing 4 (1) (2013) 1-13

Table 2.Parameter estimates with and without "quickening odds", their impacts on mean, dispersion, system's busy level, p-value for $\mathrm{H}_{0}: \phi=0$ and power of accepting $\mathrm{H}_{1}: \phi^{*}=0.5$

\begin{tabular}{|c|c|c|c|c|c|c|c|c|c|c|c|c|}
\hline Yr,Quarter & $\bar{\phi}_{\mathrm{mel}}$ & $\widehat{\phi}_{\text {mel, }, \bar{\phi} \text { mle }}$ & $\hat{\theta}_{\text {mel }, \bar{\phi} \text { mle }=0}$ & $\mathrm{a}_{\phi, \theta}$ & $\mathrm{a}_{\text {mean }, \phi, \theta}$ & $\mathrm{a}_{\text {variance, } \phi, \theta}$ & $a_{\text {busy }, \phi, \theta}(1)$ & $\mathrm{P}(\mathrm{R}>0.5)$ & pValue & Power & odds $_{\phi}$ & $\operatorname{odds}_{\phi, \theta}$ \\
\hline 1982, Q1 & 0.912 & 0.151 & 0.916 & 2.265 & 0.403 & 0.838 & 1.8492 & 0.554256 & $5.20 \mathrm{E}-05$ & $4.00 \mathrm{E}-04$ & 10.35 & 24.65 \\
\hline 1982, Q2 & 0.947 & 0.117 & 0.922 & 2.215 & 0.294 & 0.874 & 1.9113 & 0.564873 & $7.60 \mathrm{E}-07$ & 0.003 & 17.81 & 26.18 \\
\hline 1982, Q3 & 0.953 & 0.094 & 0.945 & 2.161 & 0.224 & 0.901 & 1.9315 & 0.562217 & $1.90 \mathrm{E}-11$ & 0.009 & 20.29 & 37.24 \\
\hline 1982, Q4 & 0.976 & 0.063 & 0.957 & 2.111 & 0.142 & 0.935 & 1.9670 & 0.573760 & 4.70E-19 & 0.026 & 40.77 & 47.32 \\
\hline 1983, Q1 & 0.981 & 0.047 & 0.969 & 2.081 & 0.103 & 0.951 & 1.9765 & 0.598687 & $9.00 \mathrm{E}-31$ & 0.043 & 52.94 & 65.62 \\
\hline 1983, Q2 & 0.994 & 0.029 & 0.976 & 2.054 & 0.062 & 0.970 & 1.9917 & 0.601831 & $8.30 \mathrm{E}-50$ & 0.071 & 153.10 & 85.19 \\
\hline 1983, Q3 & 0.996 & 0.026 & 0.978 & 2.049 & 0.062 & 0.973 & 1.9930 & 0.611652 & $2.20 \mathrm{E}-56$ & 0.078 & 179.90 & 92.70 \\
\hline 1983, Q4 & 0.997 & 0.023 & 0.980 & 2.044 & 0.048 & 0.976 & 1.9949 & 0.609265 & $1.60 \mathrm{E}-65$ & 0.086 & 248.30 & 102.30 \\
\hline 1984, Q1 & 0.997 & 0.017 & 0.985 & 2.033 & 0.036 & 0.982 & 1.9962 & 0.606182 & $2.80 \mathrm{E}-97$ & 0.103 & 315.40 & 137.30 \\
\hline 1984, Q2 & 0.997 & 0.015 & 0.988 & 2.027 & 0.030 & 0.985 & 1.9967 & 0.601002 & $4.00 \mathrm{E}-123$ & 0.114 & 351.60 & 164.50 \\
\hline 1984, Q3 & 0.998 & 0.013 & 0.989 & 2.024 & 0.027 & 0.987 & 1.9968 & 0.601526 & $7.00 \mathrm{E}-145$ & 0.120 & 352.90 & 187.30 \\
\hline 1984, Q4 & 0.998 & 0.012 & 0.990 & 2.022 & 0.024 & 0.988 & 1.9972 & 0.602589 & $5.00 \mathrm{E}-168$ & 0.127 & 400.00 & 209.80 \\
\hline 1985, Q1 & 0.998 & 0.010 & 0.992 & 2.018 & 0.020 & 0.990 & 1.9978 & 0.604369 & 0 & 0.138 & 499.20 & 255.30 \\
\hline 1985, Q2 & 0.998 & 0.008 & 0.993 & 2.015 & 0.016 & 0.992 & 1.9983 & 0.600440 & 0 & 0.149 & 623.10 & 305.40 \\
\hline 1985, Q3 & 0.999 & 0.007 & 0.994 & 2.013 & 0.014 & 0.993 & 1.9984 & 0.604213 & 0 & 0.156 & 657.60 & 355.70 \\
\hline 1985, Q4 & 0.999 & 0.007 & 0.995 & 2.012 & 0.014 & 0.993 & 1.9986 & 0.599696 & 0 & 0.159 & 746.20 & 367.40 \\
\hline 1986, Q1 & 0.998 & 0.006 & 0.996 & 2.010 & 0.011 & 0.994 & 1.9984 & 0.585430 & 0 & 0.168 & 809.00 & 446.50 \\
\hline 1986, Q2 & 0.999 & 0.005 & 0.996 & 2.010 & 0.011 & 0.995 & 1.9988 & 0.598604 & 0 & 0.171 & 630.00 & 528.80 \\
\hline 1986, Q3 & 0.999 & 0.005 & 0.997 & 2.008 & 0.009 & 0.996 & 1.9987 & 0.601272 & 0 & 0.179 & 884.30 & 588.80 \\
\hline $1986, \mathrm{Q} 4$ & 0.999 & 0.004 & 0.997 & 2.007 & 0.008 & 0.997 & 1.9989 & 0.600018 & 0 & 0.183 & 784.90 & 701.90 \\
\hline 1987, Q1 & 0.999 & 0.003 & 0.998 & 2.006 & 0.007 & 0.997 & 1.9990 & 0.606213 & 0 & 0.192 & 918.00 & 852.30 \\
\hline 1987, Q2 & 0.999 & 0.003 & 0.998 & 2.005 & 0.006 & 0.997 & 1.9992 & 0.616154 & 0 & 0.198 & 1026.00 & 1128.00 \\
\hline 1987, Q3 & 0.999 & 0.003 & 0.998 & 2.004 & 0.005 & 0.998 & 1.9992 & 0.626100 & 0 & 0.205 & 1211.00 & 1261.00 \\
\hline 1987, Q4 & 0.999 & 0.002 & 0.998 & 2.004 & 0.005 & 0.998 & 1.9993 & 0.635514 & 0 & 0.209 & 1343.00 & 1514.00 \\
\hline 1988, Q1 & 0.999 & 0.002 & 0.999 & 2.003 & 0.004 & 0.998 & 1.9993 & 0.644970 & 0 & 0.216 & 1517.00 & 1709.00 \\
\hline 1988, Q2 & 0.999 & 0.002 & 0.999 & 2.003 & 0.004 & 0.998 & 1.9992 & 0.649482 & 0 & 0.218 & 1538.00 & 1921.00 \\
\hline 1988, Q3 & 0.999 & 0.002 & 0.999 & 2.003 & 0.004 & 0.998 & 1.9991 & 0.658648 & 0 & 0.218 & 1306.00 & 2182.00 \\
\hline 1988, Q4 & 0.999 & 0.002 & 0.999 & 2.003 & 0.004 & 0.998 & 1.9991 & 0.673566 & 0 & 0.217 & 1143.00 & 2706.00 \\
\hline 1989, Q1 & 0.999 & 0.002 & 0.999 & 2.002 & 0.003 & 0.998 & 1.9988 & 0.688098 & 0 & 0.220 & 1111.00 & 3294.00 \\
\hline 1989, Q2 & 0.999 & 0.002 & 0.999 & 2.002 & 0.004 & 0.998 & 1.9977 & 0.710211 & 0 & 0.213 & 829.60 & 3915.00 \\
\hline 1989, Q3 & 0.998 & 0.003 & 0.999 & 2.003 & 0.006 & 0.997 & 1.9965 & 0.760250 & 0 & 0.193 & 446.00 & 4633.00 \\
\hline 1989, Q4 & 0.997 & 0.004 & 1.000 & 2.004 & 0.008 & 0.996 & 1.9995 & 0.900124 & 0 & 0.174 & 289.50 & 5926.00 \\
\hline 1990, Q1 & 0.999 & 9E-04 & 1.000 & 2.001 & 0.002 & 0.999 & 1.9995 & 0.900124 & 0 & 0.235 & 1907.00 & 5926.00 \\
\hline
\end{tabular}

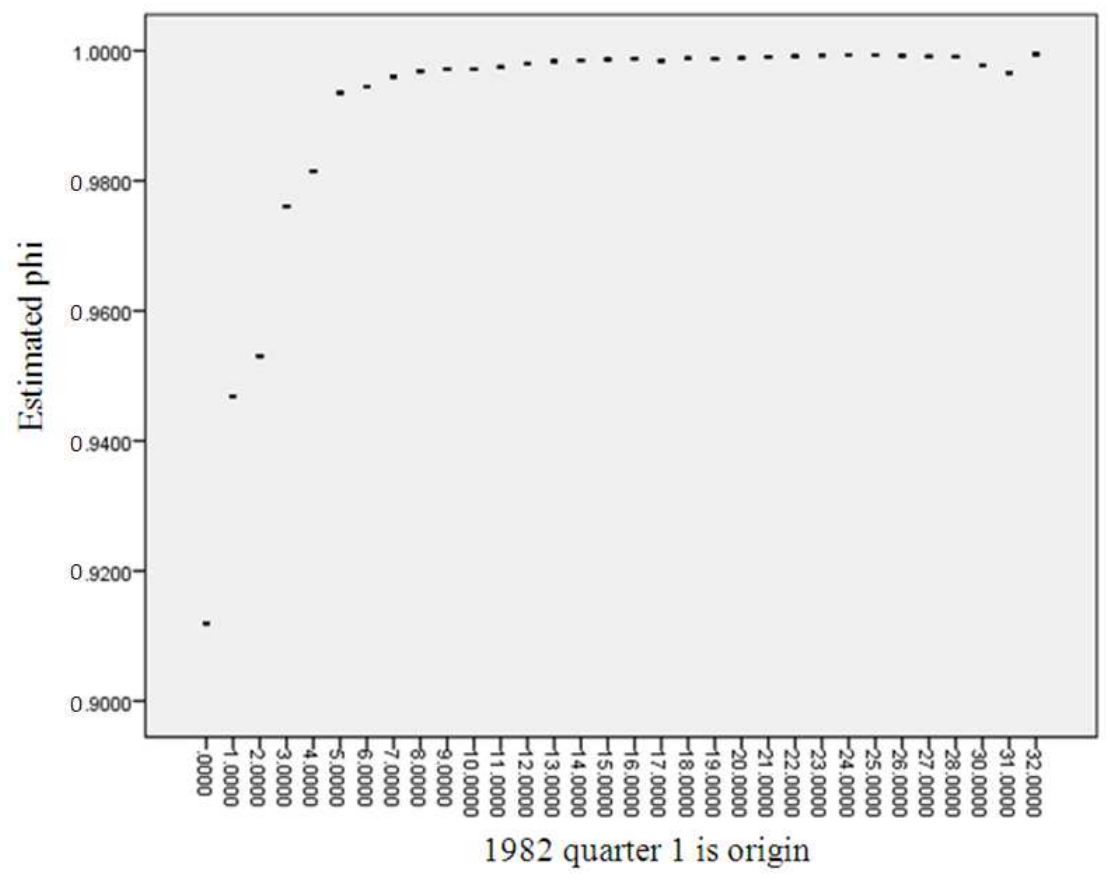

Fig. 1. Chance of "quickening" to report a delayed AIDS case 
Ramalingam Shanmugam / International Journal of Research in Nursing 4 (1) (2013) 1-13

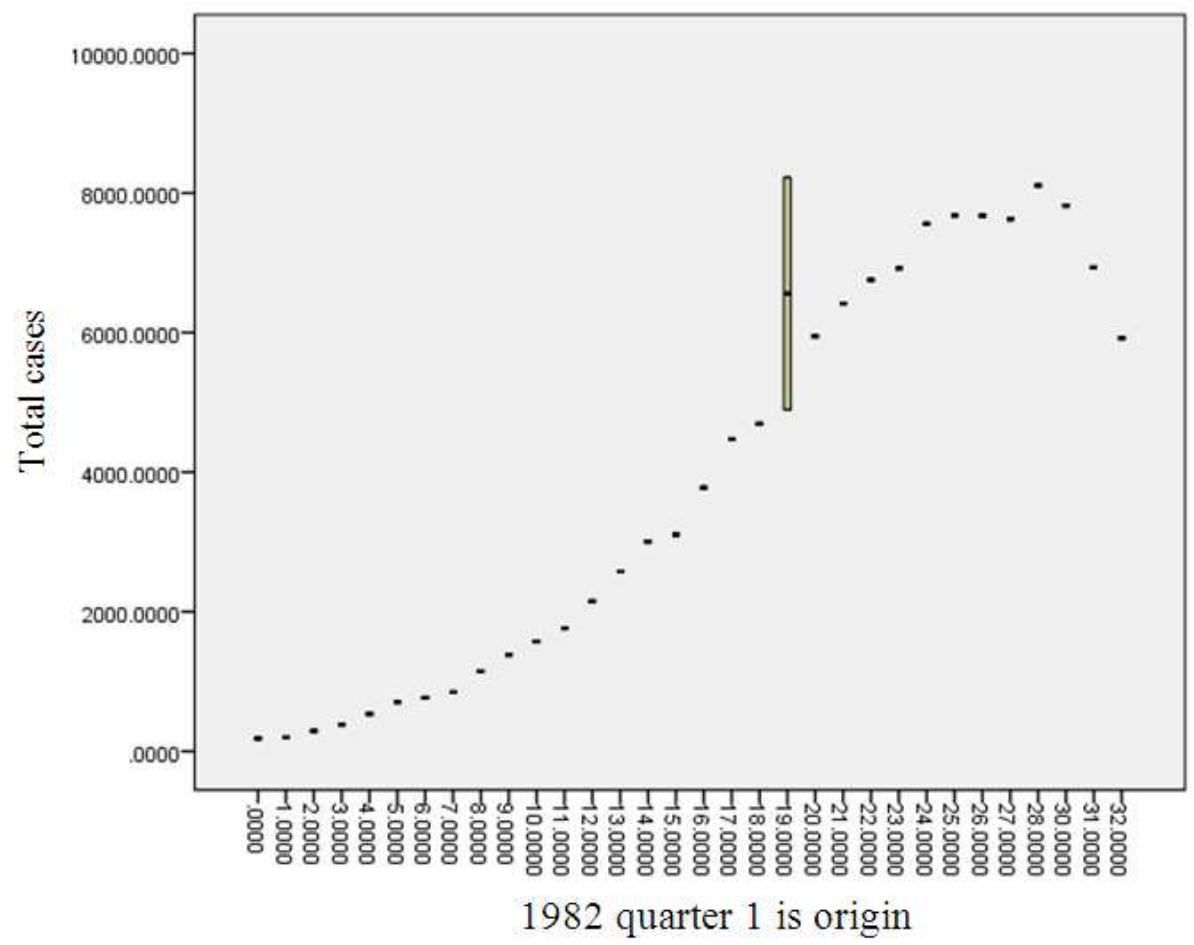

Fig. 2. The total number of reported AIDS cases over the years

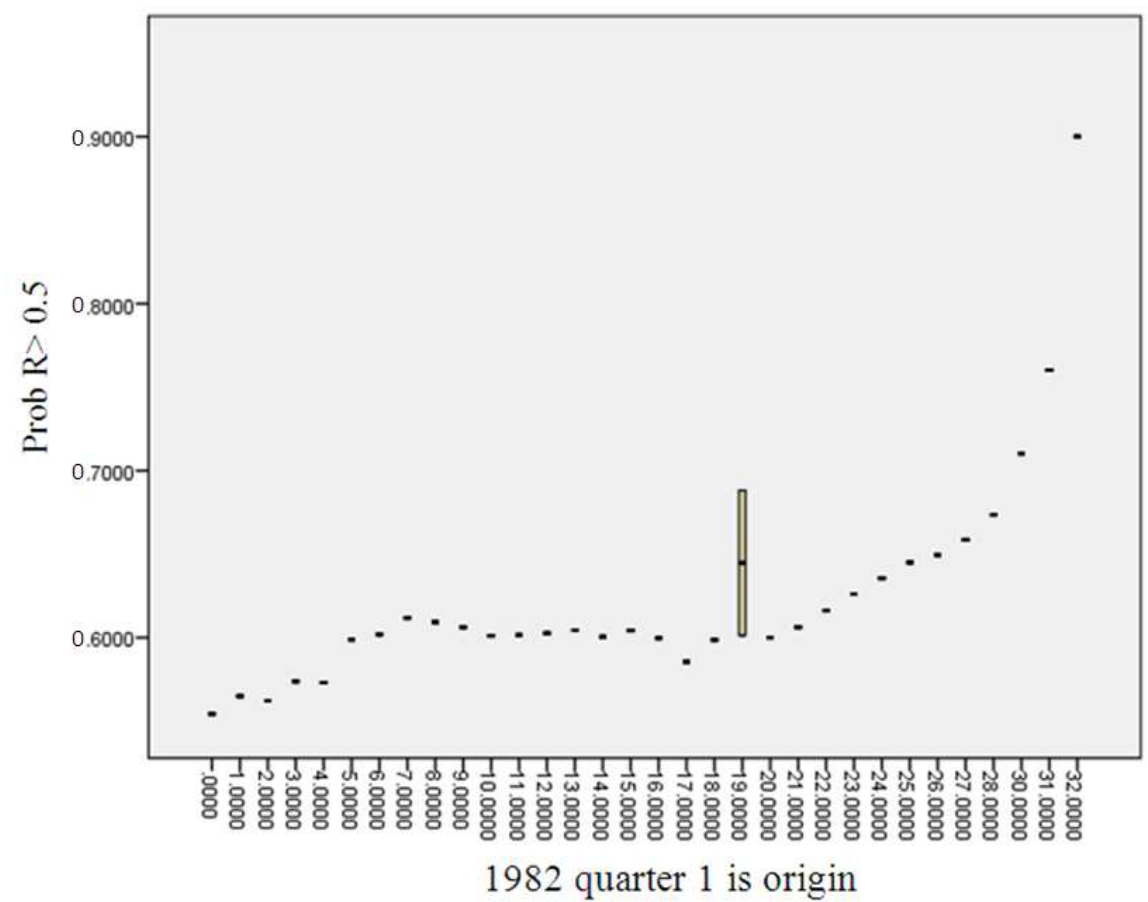

Fig. 3. Chance to report majority of the AIDS cases in the quarter of its occurrence 
Ramalingam Shanmugam / International Journal of Research in Nursing 4 (1) (2013) 1-13

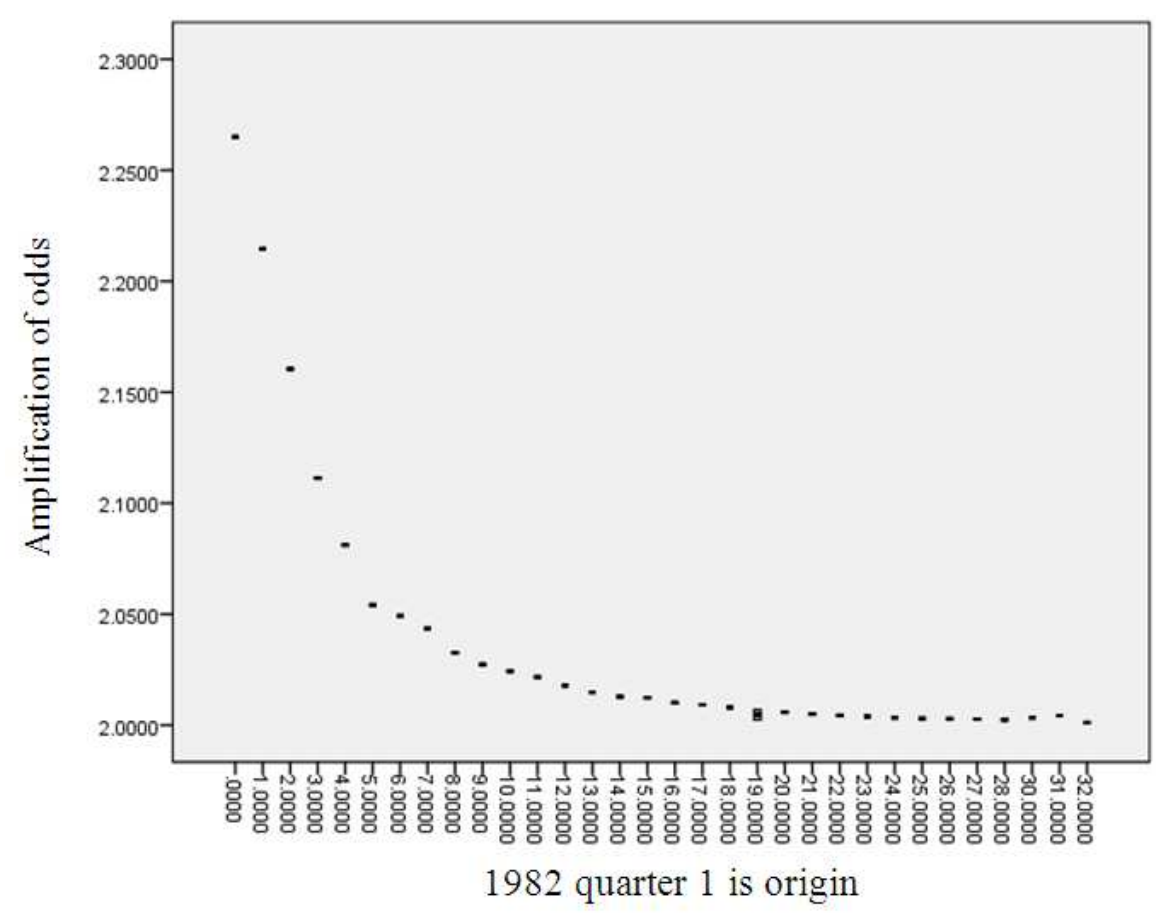

Fig. 4. Impact of "quickening odds" to report a delayed AIDS case

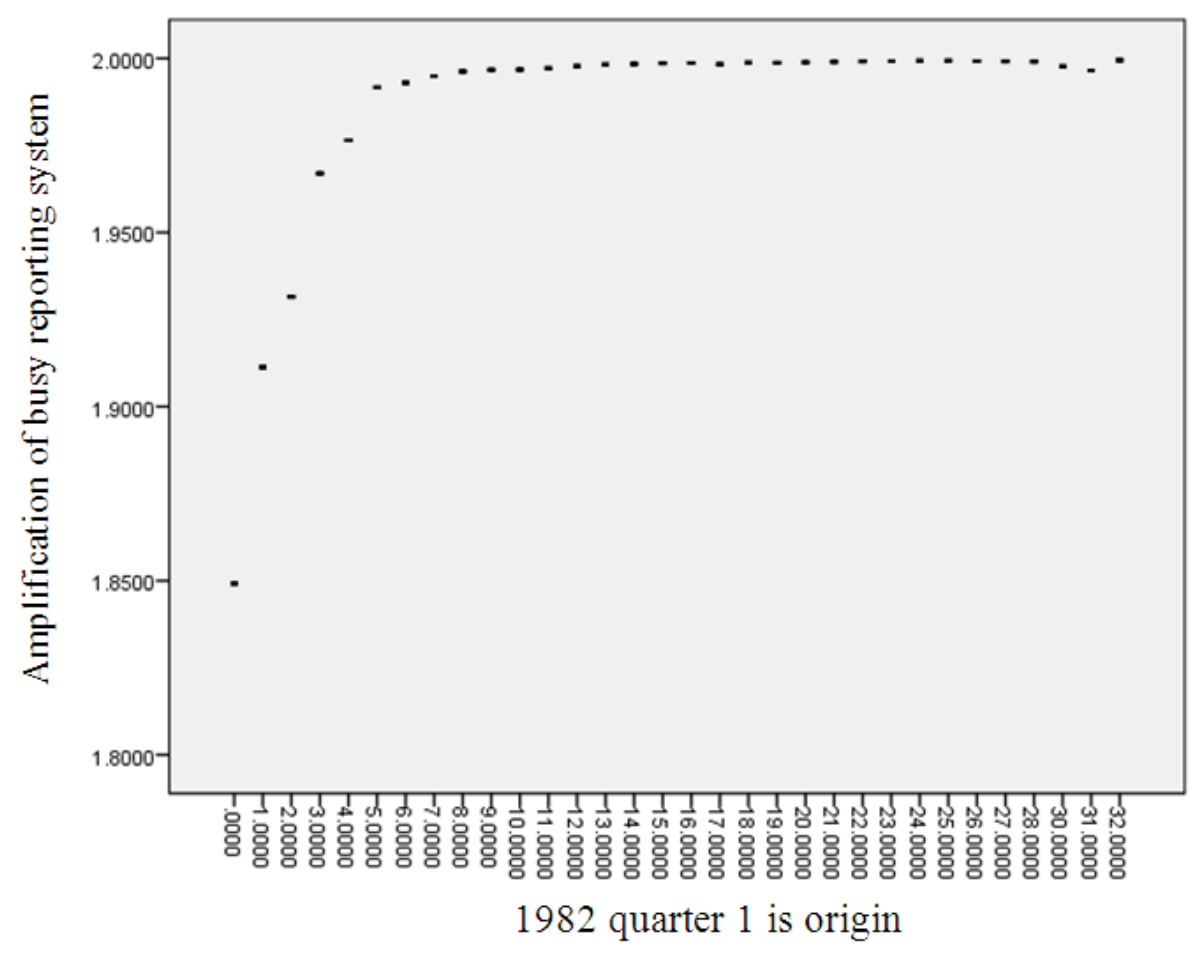

Fig. 5. Impact of "quickening odds" to report an AIDS case on system's busy level 
Ramalingam Shanmugam / International Journal of Research in Nursing 4 (1) (2013) 1-13

Table 3. Reporting system's memory with "quickening odds "to report delayed AIDS cases

\begin{tabular}{|c|c|c|c|c|c|c|c|c|c|c|c|c|c|c|c|c|}
\hline & \multirow{2}{*}{$\begin{array}{l}1,16 \\
0.984\end{array}$} & \multirow{2}{*}{$\begin{array}{l}2,16 \\
0.969\end{array}$} & \multirow{2}{*}{$\begin{array}{l}3,16 \\
0.956\end{array}$} & \multirow{2}{*}{$\begin{array}{l}4,16 \\
0.943\end{array}$} & \multirow{2}{*}{$\begin{array}{l}5,16 \\
0.931\end{array}$} & \multirow{2}{*}{$\begin{array}{l}6,16 \\
0.920\end{array}$} & \multirow{2}{*}{$\begin{array}{l}7,16 \\
0.910\end{array}$} & \multirow{2}{*}{$\begin{array}{l}8,16 \\
0.900\end{array}$} & \multirow{2}{*}{$\begin{array}{l}9,16 \\
0.891\end{array}$} & \multirow{2}{*}{$\frac{10,16}{0.882}$} & \multirow{2}{*}{$\begin{array}{l}11,16 \\
0.874\end{array}$} & \multirow{2}{*}{$\begin{array}{l}12,16 \\
0.8664\end{array}$} & \multirow{2}{*}{$\begin{array}{l}13,16 \\
0.859\end{array}$} & \multirow{2}{*}{$\begin{array}{l}14,16 \\
0.852\end{array}$} & \multirow{2}{*}{$\frac{15,16}{0.846}$} \\
\hline \multicolumn{2}{|c|}{ Yr,Quarter $(\mathrm{m}, \mathrm{t})=0,16$} & & & & & & & & & & & & & & & \\
\hline 1982, Q2 & 1 & 0.986 & 0.972 & 0.960 & 0.948 & 0.937 & 0.927 & 0.917 & 0.908 & 0.899 & 0.891 & 0.884 & 0.8763 & 0.869 & 0.863 & 0.857 \\
\hline 1982, Q3 & 1 & 0.992 & 0.984 & 0.977 & 0.970 & 0.963 & 0.957 & 0.950 & 0.945 & 0.939 & 0.934 & 0.929 & 0.9236 & 0.919 & 0.914 & 0.910 \\
\hline 1982, Q4 & 1 & 0.995 & 0.989 & 0.984 & 0.979 & 0.975 & 0.970 & 0.966 & 0.962 & 0.958 & 0.954 & 0.950 & 0.9465 & 0.943 & 0.940 & 0.936 \\
\hline 1983, Q1 & 1 & 0.997 & 0.994 & 0.991 & 0.988 & 0.985 & 0.983 & 0.980 & 0.978 & 0.975 & 0.973 & 0.970 & 0.9682 & 0.966 & 0.964 & 0.962 \\
\hline 1983, Q2 & 1 & 0.998 & 0.996 & 0.994 & 0.993 & 0.991 & 0.989 & 0.987 & 0.986 & 0.984 & 0.983 & 0.981 & 0.9795 & 0.978 & 0.977 & 0.975 \\
\hline 1983, Q3 & 1 & 0.998 & 0.997 & 0.995 & 0.994 & 0.992 & 0.991 & 0.989 & 0.988 & 0.986 & 0.985 & 0.984 & 0.9822 & 0.981 & 0.980 & 0.978 \\
\hline 1983, Q4 & 1 & 0.999 & 0.997 & 0.996 & 0.995 & 0.993 & 0.992 & 0.991 & 0.990 & 0.988 & 0.987 & 0.986 & 0.9850 & 0.984 & 0.983 & 0.982 \\
\hline 1984, Q1 & 1 & 0.999 & 0.998 & 0.998 & 0.997 & 0.996 & 0.995 & 0.995 & 0.994 & 0.993 & 0.993 & 0.992 & 0.9911 & 0.990 & 0.990 & 0.989 \\
\hline 1984, Q2 & 1 & 0.999 & 0.999 & 0.998 & 0.998 & 0.997 & 0.997 & 0.996 & 0.996 & 0.995 & 0.995 & 0.994 & 0.9936 & 0.993 & 0.993 & 0.992 \\
\hline 1984, Q3 & 1 & 1.000 & 0.999 & 0.999 & 0.998 & 0.998 & 0.997 & 0.997 & 0.997 & 0.996 & 0.996 & 0.995 & 0.9950 & 0.995 & 0.994 & 0.994 \\
\hline 1984, Q4 & 1 & 1.000 & 0.999 & 0.999 & 0.999 & 0.998 & 0.998 & 0.998 & 0.997 & 0.997 & 0.997 & 0.996 & 0.9959 & 0.996 & 0.995 & 0.995 \\
\hline 1985, Q1 & 1 & 1.000 & 1.000 & 0.999 & 0.999 & 0.999 & 0.999 & 0.998 & 0.998 & 0.998 & 0.998 & 0.997 & 0.9972 & 0.997 & 0.997 & 0.997 \\
\hline 1985, Q2 & 1 & 1.000 & 1.000 & 0.999 & 0.999 & 0.999 & 0.999 & 0.999 & 0.999 & 0.998 & 0.998 & 0.998 & 0.9980 & 0.998 & 0.998 & 0.998 \\
\hline 1985, Q3 & 1 & 1.000 & 1.000 & 1.000 & 0.999 & 0.999 & 0.999 & 0.999 & 0.999 & 0.999 & 0.999 & 0.999 & 0.9985 & 0.998 & 0.998 & 0.998 \\
\hline 1985, Q4 & 1 & 1.000 & 1.000 & 1.000 & 1.000 & 0.999 & 0.999 & 0.999 & 0.999 & 0.999 & 0.999 & 0.999 & 0.9986 & 0.998 & 0.998 & 0.998 \\
\hline 1986, Q1 & 1 & 1.000 & 1.000 & 1.000 & 1.000 & 1.000 & 1.000 & 0.999 & 0.999 & 0.999 & 0.999 & 0.999 & 0.9990 & 0.999 & 0.999 & 0.999 \\
\hline 1986, Q2 & 1 & 1.000 & 1.000 & 1.000 & 1.000 & 1.000 & 1.000 & 1.000 & 1.000 & 0.999 & 0.999 & 0.999 & 0.9993 & 0.999 & 0.999 & 0.999 \\
\hline 1986, Q3 & 1 & 1.000 & 1.000 & 1.000 & 1.000 & 1.000 & 1.000 & 1.000 & 1.000 & 1.000 & 1.000 & 1.000 & 0.9995 & 0.999 & 0.999 & \\
\hline$\backslash 1986, \mathrm{Q} 4$ & 1 & 1.000 & 1.000 & 1.000 & 1.000 & 1.000 & 1.000 & 1.000 & 1.000 & 1.000 & 1.000 & 1.000 & 0.9997 & & & \\
\hline 1987, Q1 & 1 & 1.000 & 1.000 & 1.000 & 1.000 & 1.000 & 1.000 & 1.000 & 1.000 & 1.000 & 1.000 & 1.000 & 0.9998 & & & \\
\hline 1987, Q2 & 1 & 1.000 & 1.000 & 1.000 & 1.000 & 1.000 & 1.000 & 1.000 & 1.000 & 1.000 & 1.000 & & & & & \\
\hline 1987, Q3 & 1 & 1.000 & 1.000 & 1.000 & 1.000 & 1.000 & 1.000 & 1.000 & 1.000 & 1.000 & 1.000 & & & & & \\
\hline 1987, Q4 & 1 & 1.000 & 1.000 & 1.000 & 1.000 & 1.000 & 1.000 & 1.000 & 1.000 & 1.000 & & & & & & \\
\hline 1988, Q1 & 1 & 1.000 & 1.000 & 1.000 & 1.000 & 1.000 & 1.000 & 1.000 & 1.000 & & & & & & & \\
\hline 1988, Q2 & 1 & 1.000 & 1.000 & 1.000 & 1.000 & 1.000 & 1.000 & 1.000 & & & & & & & & \\
\hline 1988, Q3 & 1 & 1.000 & 1.000 & 1.000 & 1.000 & 1.000 & 1.000 & & & & & & & & & \\
\hline 1988, Q4 & 1 & 1.000 & 1.000 & 1.000 & 1.000 & 1.000 & & & & & & & & & & \\
\hline 1989, Q1 & 1 & 1.000 & 1.000 & 1.000 & 1.000 & & & & & & & & & & & \\
\hline 1989, Q2 & 1 & 1.000 & 1.000 & 1.000 & & & & & & & & & & & & \\
\hline 1989, Q3 & 1 & 1.000 & 1.000 & & & & & & & & & & & & & \\
\hline 1989, Q4 & 1 & 1.000 & & & & & & & & & & & & & & \\
\hline 1990, Q1 & 1 & & & & & & & & & & & & & & & \\
\hline
\end{tabular}

The $a_{\text {busy, } \phi, \theta}$ captures the impact of "quickening odds" to report on system's busy level (Table 2). According to their values, the impact has been increasing from 1.84 to 1.99 over the years during 1982 through 1990. With notations $\mathrm{Y}$ and $\mathrm{T}-\mathrm{Y}$ denoting respectively the number of reported, non-reported cases with $\mathrm{m}=0.5$ indicating the reported cases is $50 \%$ more than the non-reported cases in the same quarter of its occurrence, the chance $\operatorname{Pr}\left[\frac{\mathrm{Y}}{\mathrm{T}-\mathrm{Y}}=\mathrm{R}>\mathrm{m}\right]$ is displayed in Table 2. Interestingly, their values suggest they had been more than 55\% but oscillated over the years during 1982 through 1990. The p-value in Table 2 indicates the chance for rejecting the true null hypothesis $\mathrm{H} \circ: \phi=0$ and it confirms the existence of a significant "odds of quickening" to report. The power in Table 2 implies the chance of accepting a true alternative hypothesis $\mathrm{H}_{1}: \phi^{*}=0.5$ with the level of significance $\alpha=0.05$. Its oscillation hints the existence of varying administrative efforts to quickly report already delayed cases in the reporting medical system. It is worth examining how the reporting system's memory had been.
In a system with the absence of "quickening odds" to report an AIDS case, the system is recognized to follow a geometric probability distribution with no memory and the system's memory level $\mathrm{m}_{\phi=0, \theta}$ is just one. With an existence of "quickening odds" to report already delayed AIDS cases, the reporting system possesses a finite memory. The Table 3 displays its memory level for the period 1982 through 1990.

\section{CONCLUSION}

This methodology is applicable to any delayed reporting system in other disciplines. In engineering, sports, e-marketing, healthcare insurance, stockmarketing, economic outcomes, cyber-crimes reporting with delay and the existence of efforts to quicken the reporting of already delayed cases are common. The contents of this article would help to discover non trivial impacts in those disciplines. Of course, many covariates are likely to influence the level of quickening efforts. A regression methodology is necessary to address the relevance of the covariates in a given investigation and it 
could be developed with the significance of an estimated effort to quicken. A regression like the one in Pagano et al. (1994) is worthwhile and it is currently pursued for publication later.

\section{REFERENCES}

Bacchetti, P., 1996. Reporting delays of deaths with AIDS in the united states. J. Acquire Immune Defic. Syndr. Hum. Retovirol., 13: 363-367.

CDC, 1985. Revision of the case definition of acquired immunodeficiency syndrome for national reporting-united states. Morb. Mortal. Weekly Rep., 34: 373-5. PMID: 2989677

Chamberland, M.E., J.R. Allen, J.M. Monroe, N. Garcia and C. Morgan, 1985. Acquired immunodeficiency syndrome in New York city. Evaluation of an active surveillance system. J. Am. Med. Assoc., 254: 383387. PMID: 4009865

Clegg, L.X., E.J. Feuer, M.P. Fay and B.F. Hankey, 2002. Impact of reporting delay and reporting error on cancer incidence rates and trends. J. National Cancer Inst., 94: 1537-45. DOI: 10.1093/jnci/94.20.1537

Cui, J., 1999. Nonparametric estimation of a delay distribution based on left-censored and righttruncated data. Biometrics, 55: 345-349. DOI: 10.1111/j.0006-341X.1999.00345.x

DeGruttola, V., X.M. Tu and M. Pagano, 1992. Pediatric AIDS in New York City: Estimating the distributions of infection, latency and reporting delay and projecting future incidence. J. Am. Stat. Assoc., 87: 633-640.

Fan, H.Y., R.F. Conner and L.P. Villarreal, 2004. AIDS: Science and Society. 4th Edn., Jones and Bartlett Learning, Boston, MA., ISBN-10: 076370086X, pp: 229.

Gebhardt, M.D., B.E. Neuenschwander and M. Zwahlen, 1998. Adjusting AIDS incidence for non-stationary reporting delays: A necessity for country comparisons. Eur. J. Epidemiol., 14: 595-503. DOI: 10.1023/A:1007406606892

Harris, J.E., 1990. Reporting delays and the incidence of AIDS. J. Am. Stat. Assoc., 85: 915-924.
Hay, J.W. and F.A. Wolak, 1994. A procedure for estimating the unconditional cumulative incidence curve and its variability for the human immunodeficiency virus. J. Royal Stat. Soc., C43: 599-624.

Lawless, J.F., 1994. Adjustments for reporting delays and the prediction of occurred but not reported events. Canadian J. Stat., 22: 15-31. DOI: 10.2307/3315826.n1

Lindsey, J.K., 1996. Fitting bivariate intensity functions, with an application to modelling delays in reporting acquired immune deficiency syndrome. J. Royal Stat. Soc., 159: 125-131.

MacArthur, C., L. Pendleton and A. Smith, 1985. Treatment delay in patients with bladder tumours. J. Epidemiol. Community Health, 39: 63-66. DOI: 10.1136/jech.39.1.63

Midthune, D.N., M.P. Fay, L.X. Clegg and E.J. Feuer, 2005. Modeling reporting delays and reporting corrections in cancer registry data. J. Am. Stat. Assoc., $\quad 100$ : $\quad 61-70 . \quad$ DOI: 10.1198/016214504000001899

Pagano, M., X.M. Tu, V.D. Gruttola and S. MaWhinney, 1994. Regression analysis of censored and truncated data: Estimating reporting-delay distributions and AIDS incidence from surveillance data. Biometrics, 50: 1203-1214. PMID: 7787003

Stuart, A. And K. Ord, 1994. Kendall's Advanced Theory of Statistics, Distribution Theory. 1st Edn., Wiley, Chichester, ISBN-10: 0470665300, pp: 700.

Tabnak, F., H.G. Müller, J.L. Wang, J.M. Chiou and R. Sun, 2000. A change-point model for reporting delays under change of AIDS case definition. Eur. J. Epidemiol., 16: 1135-1141. DOI: 10.1023/A:1010955827954

Wald, A., 1943. Tests of statistical hypotheses concerning several parameters when the number of observations is large. Trans. Am. Math. Soc., 54: 426-482.

Zou, J., L. Huang, D. Midthune, M.J. Horner and M. Krapcho et al., 2009. Effect of reporting year on delay modeling. Stat. Res. Applic. Branch, NCI. 